\title{
Antimicrobial Resistance of Neisseria Gonorrhoeae in a Newly Implemented Surveillance Program in Uganda: Surveillance Report
}

Meklit Workneh $^{1 *}$, MD, MPH; Matthew M Hamill ${ }^{*}$, PhD, FRCP; Francis Kakooza², BSc, MSc; Emmanuel Mande ${ }^{2}$, BSc; Jessica Wagner ${ }^{3}$, MPH; Olive Mbabazi ${ }^{2}$, MSc; Rodney Mugasha ${ }^{2}$, BSc; Henry Kajumbula ${ }^{2}$, MBChB; Richard Walwema $^{2}$, MBA; Jonathan Zenilman ${ }^{1}$, MD; Patrick Musinguzi ${ }^{4}$, MBChB; Peter Kyambadde ${ }^{4}$, MBChB, MPH, DPM; Mohammed Lamorde ${ }^{2}$, PhD, FRCP; Yukari C Manabe ${ }^{1,2}$, MD

\footnotetext{
${ }^{1}$ Division of Infectious Diseases, Johns Hopkins School of Medicine, Baltimore, MD, United States

${ }^{2}$ Infectious Disease Institute, Kampala, Uganda

${ }^{3}$ Bayview Pediatric Unit, Johns Hopkins University, Baltimore, MD, United States

${ }^{4}$ AIDS Control Program, Division of Sexually Transmitted Infections, Ministry of Health, Kampala, Uganda

these authors contributed equally
}

\section{Corresponding Author:}

Matthew M Hamill, PhD, FRCP

Division of Infectious Diseases

Johns Hopkins School of Medicine

5200 Eastern Avenue

Baltimore, MD, 21224

United States

Phone: 14105509080

Email: mhamill6@jhu.edu

\section{Abstract \\ Background: Neisseria gonorrhoeae (commonly known as gonorrhea) has developed resistance to all first-line therapy in Southeast Asia. East Africa has historically had absent or rudimentary gonorrhea surveillance programs and, while the existence of antimicrobial-resistant gonorrhea is recognized, the extent of its resistance is largely unknown. In 2016, the World Health Organization's Enhanced Gonococcal Antimicrobial Surveillance Program (EGASP) was initiated in Uganda to monitor resistance trends.}

Objective: This study characterizes gonorrhea and antibiotic resistance in a large surveillance program of men with urethral discharge syndrome from Kampala, Uganda.

Methods: Men attending sentinel clinics with urethritis provided demographic information, behavior data, and a urethral swab in line with the World Health Organization's EGASP protocols for culture, identification, and antibiotic-sensitivity testing using 2 methods_-disk diffusion (Kirby-Bauer test) and Etest (BioMérieux Inc). A subset of samples underwent detailed antimicrobial resistance testing.

Results: Of 639 samples collected from September 2016 to February 2018, 400 (62.6\%) were culture-positive though 414 $(64.8 \%)$ had microscopic evidence of gonorrhea. The mean age of the men from whom the samples were collected was 26.9 (SD 9.6) years and 7.2\% (46/639) reported having HIV. There was high-level resistance to ciprofloxacin, tetracycline, and penicillin (greater than $90 \%$ ) by Kirby-Bauer disk diffusion and 2.1\% (4/188) had reduced azithromycin sensitivity by Etest. Of the early isolates that underwent detailed characterization, 60.3\% (70/116) were culture-positive, 94\% (66/69) isolates were either ciprofloxacin-resistant or ciprofloxacin-intermediate by Etest, 96\% (65/68) were azithromycin-sensitive, and 96\% (66/69) were gentamicin-sensitive. Resistance profiles were comparable between methods except for ceftriaxone (disk diffusion: 68/69, 99\%; Etest: $67 / 69,97 \%$ ) and for gentamicin (disk diffusion: 2/8, 25\%; Etest: 66/69, 96\%) sensitivity.

Conclusions: This is the first report from a systematic gonorrhea surveillance program in Uganda. Findings demonstrated resistance or increased minimum inhibitory concentration to all key antigonococcal antibiotics. There was evidence of poor antibiotic stewardship, near-universal resistance to several antibiotics, and emerging resistance to others. Individuals in the population sampled were at exceptionally high risk of STI and HIV infection requiring intervention. Ongoing surveillance efforts to develop interventions to curtail antimicrobial-resistant gonorrhea are needed. 
(JMIR Public Health Surveill 2020;6(2):e17009) doi: 10.2196/17009

\section{KEYWORDS}

gonorrhea; antimicrobial resistance; surveillance; Uganda; STD; STI; sexually transmitted; Neisseria Gonorrhoeae; antibiotic resistance, EGASP

\section{Introduction}

Neisseria gonorrhoeae (also known as gonorrhea) is a common sexually transmitted infection (STI) and a major cause of morbidity. Gonorrhea has developed antimicrobial resistance to all classes of antibiotics used in its treatment. Gonorrhea can cause sequelae such as pelvic inflammatory disease with resultant ectopic pregnancy [1] and increases HIV transmission [2]. In 2016, 86.9 million of an estimated 376.4 million new, curable STIs in adults aged 15 to 49 years were attributed to gonorrhea [3]. In 2016, the global annual incidence rate of gonorrhea was estimated at $2.6 \%$ among men and $2.0 \%$ among women. In Africa, the incidence rates were $1.6 \%$ and $1.9 \%$ among men and women, respectively [3], which was an increase from 2012 [4]. In the 1970s, gonococcal plasmid- and chromosomally mediated resistance to penicillin and tetracycline emerged in Asia, and within a decade, had spread globally [5]. High-level fluoroquinolone resistance evolved in the early to mid 2000s [6]. Third-generation extended-spectrum cephalosporins are the mainstay of gonorrhea therapy in many regions; however, their minimum inhibitory concentration has been increasing since their widespread introduction as a treatment for gonorrhea. More recently, clinical gonorrhea isolates with high azithromycin minimum inhibitory concentration have been recognized and increasingly reported $[5,7]$.

Cases of highly resistant gonorrhea have been reported in several regions [8-10] and likely represent international clonal expansion $[11,12]$. Sub-Saharan African gonorrhea data are minimal [13-17]; gonorrhea resistance has been documented in Uganda $[18,19]$, but its prevalence is unknown. In 2016, the WHO initiated its Enhanced Gonococcal Antimicrobial Surveillance Program (EGASP) in Uganda to monitor patterns of resistance. The Gonococcal Antimicrobial Surveillance Program (GASP) had been in place since 1992 to monitor antimicrobial resistance worldwide with the aim of informing treatment guidelines [20]. The WHO released the Baseline Report on Sexually Transmitted Infection Surveillance [21] in 2012, at which time there were no GASP regional focal points in Africa; in contrast, in all other WHO regions, there was at least one. In addition, only 5 countries in Africa were participating in GASP at that point in time which was an inadequate response given the burden of gonococcal disease in the region [4]. WHO GASP data from 2009 to 2014 [22] which were reported from 3 sites in Africa (South Africa, Kenya, and Côte d'Ivoire) showed persistent and widespread resistance to penicillin, tetracycline, and ciprofloxacin; increasing resistance to azithromycin (greater than 5\%); and emerging resistance and decreased susceptibility to extended-spectrum cephalosporins (although only 15\% of countries in Africa reported extended-spectrum cephalosporin data). Data collected from 2015 to 2016 in Zimbabwe described $9.5 \%-30.8 \%$ ciprofloxacin resistance and $100 \%$ sensitivity to extended-spectrum cephalosporins [23]. With EGASP, the WHO aimed to address the limitations that were identified in implementing GASP [20]. EGASP protocols standardize sampling strategies, laboratory methods, demographic information, and quality assurance procedures for use in sentinel surveillance sites in selected countries. Focusing EGASP on resource-limited settings allows more detailed scrutiny of the global burden of antimicrobial resistance in areas where prevalence is high. EGASP strengthens and streamlines reporting mechanisms for specified alert values for antimicrobial resistance, thus facilitating timely responses. In Uganda, EGASP represents a collaboration between the National STI Control Program at the Ugandan Ministry of Health, the Infectious Disease Institute in Kampala, and is carried out in partnership with the Centers for Disease Control and Prevention to implement a gonorrhea surveillance program. Herein, we report initial antimicrobial resistance and epidemiological results of the gonorrhea surveillance program in Kampala, Uganda.

\section{Methods}

\section{Clinical Setting}

Between September 2016 and February 2018, urethral samples were collected from men at nine sentinel clinics in and around Kampala, Uganda. Clinics were selected after reviewing health management information system records at the Ministry of Health and were based upon their ability to meet several criteria. Clinics were required to have high patient volumes in order to collect a sufficient number of samples regularly, an ability to collect data in accordance with Uganda's national STI guidelines which involved recording a patient's full medical history and performing a clinical examination (see Multimedia Appendix 1 ), and the capacity to collect and maintain sample viability until transportation to the reference laboratory. In order for samples to be properly collected, trained clinical staff were required, and to ensure safe handling of samples, a system for storage until samples were collected and transported (which occurred daily) was required.

\section{Sample Collection and Testing}

Urethral Amies swabs without charcoal (Deltalab SL) were used to consecutively collect specimens from men who presented with urethral discharge syndrome. Samples were stored at ambient temperature and atmosphere and were transported within 12 hours to the designated reference laboratory site in Kampala (Infectious Disease Institute Translational Laboratory). Samples were inoculated on modified Thayer-Martin and chocolate agar and incubated between $35^{\circ} \mathrm{C}$ and $36.5^{\circ} \mathrm{C}$ in $5 \%$ carbon dioxide. Isolation and confirmation of $N$ gonorrhoeae was performed with technical assistance from the Department of Microbiology, Makerere University. Presumptive identification of $N$ gonorrhoeae was based upon (1) growth of typical colonies on modified Thayer-Martin agar between $35^{\circ} \mathrm{C}$ 
and $36.5^{\circ} \mathrm{C}$ in $5 \%$ carbon dioxide, (2) a positive oxidase test, and (3) observation of Gram-negative, oxidase-positive diplococci in stained smears. Antimicrobial susceptibility tests using Kirby-Bauer disk diffusion were performed for the following antibiotics: penicillin, tetracycline, ciprofloxacin, cefoxitin, gentamicin, spectinomycin, ceftriaxone, and cefixime. Additional antimicrobial susceptibility tests were performed using Etest strips (BioMérieux Inc) to determine minimum inhibitory concentration for a subset of isolates for the following priority antibiotics: cefixime, ceftriaxone, cefuroxime, ciprofloxacin, azithromycin, and gentamicin on gonococcal medium base inoculated with $10^{4}$ colony forming units. Etest strips are expensive and difficult to source in Uganda, and therefore, were used routinely early in the program, after which disk diffusion was used routinely to determine antimicrobial susceptibility. Presumptive $N$ gonorrhoeae isolates with minimum inhibitory concentrations that exceeded criteria specified by EGASP protocols (antibiotic alert value criteria: ceftriaxone, $\geq 0.125 \mu \mathrm{g} / \mathrm{mL}$; cefixime, $\geq 0.25 \mu \mathrm{g} / \mathrm{mL}$; azithromycin, $\geq 2 \mu \mathrm{g} / \mathrm{mL}$; gentamicin $\geq 16 \mu \mathrm{g} / \mathrm{mL}$ ) underwent additional Etest analysis according to Biochemical Test Clinical and Laboratory Standards Institute Guidelines within five working days.

\section{Quality Assurance and Quality Control}

Due to constraints on resources, the EGASP-recommended WHO $N$ gonorrhoeae $\mathrm{K}$ and L control strains were not used. Alternative quality measures that could be locally implemented were used. The Becton-Dickinson control strain (American Type Culture Collection; ATCC 49226) was used in the place of WHO $N$ gonorrhoeae $\mathrm{K}$ and L strains. Control tests were carried out monthly or upon receipt of a new batch of antimicrobial susceptibility disks, Etest strips, or the introduction of a new batch of media. Isolate identification was performed to ensure consistency in methods and the zones of clearance for the control strain were compared to the reference standards for each drug.

\section{Data Management and Analysis}

Demographic and behavior data were collected using the combined WHO-Ministry of Health Uganda data collection form, albeit the same-sex sexual activity question was removed to reduce the risk of harm to respondents [24]. Data were manually entered into Access database software (Microsoft Inc) prior to data analysis. Minor amendments were made to the questionnaire partway through the time period under review to be more realistic in expectations of the individual's ability to recollect events and to reduce the chance of recall bias- the period for number of gonorrhea episodes and number of sex partners was reduced from 12 to 6 months. Similarly, the period for recent, previsit antibiotic use was reduced from 60 to 14 days. These differences were reflected in the different timeframes used for reporting. Antimicrobial susceptibility data were exported to WHONet, a WHO information system for managing, analyzing, and reporting antimicrobial resistance data. If confirmed, minimum inhibitory concentrations that exceeded alert criteria were promptly reported to the Ministry of Health and to sentinel clinics.
Disk diffusion for isolates for all antibiotics, with the exception of cefoxitin, were reported. Etests were used for an initial subset of 116 isolates as well as for some later specimens (if Etest strips were available) or when isolates met minimum inhibitory concentration alert value criteria. Data on cefoxitin were included in the comprehensive analysis of 116 samples using Etest. $P$ values $\leq .05$ were deemed statistically significant. Data were compared using two-tailed independent $t$ tests with unequal variance for continuous variables and using the chi-square test for categorical variables. Odds ratios (OR) and their associated confidence intervals were calculated using logistic regression. All analyses were performed using SAS statistical software (version 9.4; SAS Institute Inc).

\section{Ethical Approval}

The gonococcal surveillance program was performed as part of public health surveillance activities under the purview of the Ugandan Ministry of Health and approved by the Director General. As the activity was permitted by the Ministry of Health in the interest of public health practice for disease surveillance in Uganda, it did not fall within the realm of research. The gonococcal surveillance program legitimately involved individuals who were not explicitly asked to provide informed consent and did not require further institutional review board approval.

\section{Results}

\section{Overall Sample Characteristics}

Results are presented for the overall sample characteristics and are further analyzed by gonorrhea culture-status.

Urethral samples $(\mathrm{N}=639)$ were collected from men whose mean age was 26.9 (SD 9.6) years, and of whom, 7.2\% (46/639) self-reported HIV-positive (Table 1). Microscopic diagnosis of presumptive gonorrhea was positively made from evidence of Gram-negative intracellular diplococci from urethral material in 414/639 (64.8\%) samples; evidence of Gram-negative intracellular diplococci was not present in 225/639 (35.2\%) of samples. Only 400 (400/414, 96.6\%; 400/639, 62.6\%) Gram-negative intracellular diplococci-positive samples on Gram staining were culture-positive, based on the growth of typical small translucent colonies on modified Thayer-Martin medium, and of these 399 (399/414, 96.4\%; 399/639, 62.4\%) were oxidase- and superoxidase-positive consistent with gonorrhea. Overall, 36\% of samples (230/639) were culture-negative. Of the culture-positive samples, $60.8 \%$ (243/400) were from individuals self-reported without HIV, $7.5 \%(30 / 400)$ were from individuals self-reported HIV-positive, and $31.8 \%$ (127/400) were from individuals whose HIV-status was unknown.

Reported condom-use was low; $2.7 \%$ (18/639) reported always using a condom and $69.3 \%$ (443/639) reported one or more sexual partners within the past 6-12 months (mean 1.4; SD 1.49; range 0-20). Full demographic, behavior, and health-related characteristics are presented in Table 1. 
Table 1. Demographic, health-related, and behavior factors.

\begin{tabular}{|c|c|}
\hline Variable & Samples $(\mathrm{N}=639), \mathrm{n}(\%)$ \\
\hline \multicolumn{2}{|l|}{ HIV-status } \\
\hline Positive & $46(7.2)$ \\
\hline Negative & $393(61.5)$ \\
\hline Unknown & $200(31.3)$ \\
\hline \multicolumn{2}{|l|}{ Condom use $^{\mathrm{a}}$} \\
\hline Always & $18(2.8)$ \\
\hline Sometimes & $403(63.1)$ \\
\hline Never & $176(27.5)$ \\
\hline \multicolumn{2}{|c|}{ Number of sex partners } \\
\hline 0 & $189(29.1)$ \\
\hline 1 & $196(31.0)$ \\
\hline 2 & $146(23.1)$ \\
\hline 3 & $61(9.7)$ \\
\hline 4 & $12(1.9)$ \\
\hline 5 & $14(2.2)$ \\
\hline 6 & $7(1.1)$ \\
\hline 7 & $1(0.2)$ \\
\hline 8 & $1(0.2)$ \\
\hline 10 & $4(0.6)$ \\
\hline 20 & $1(0.2)$ \\
\hline \multicolumn{2}{|l|}{ Symptoms } \\
\hline Discharge & $590(88.2)$ \\
\hline Dysuria & $553(86.5)$ \\
\hline Other & $36(5.6)$ \\
\hline \multicolumn{2}{|c|}{ Previous history of gonorrhea } \\
\hline Yes & $286(44.8)$ \\
\hline No & $353(55.2)$ \\
\hline \multicolumn{2}{|l|}{ Sex for money ${ }^{b}$} \\
\hline Yes & $98(15.3)$ \\
\hline No & $541(84.7)$ \\
\hline \multicolumn{2}{|c|}{ Recent antibiotic use $^{d}$} \\
\hline Yes & $209(32.7)$ \\
\hline No & $430(67.3)$ \\
\hline
\end{tabular}

${ }_{n}=42$ responses were missing.

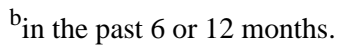

${ }^{c} \mathrm{n}=7$ responses were missing.

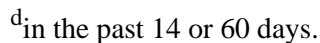

\section{Resistance Profiles}

Table 2 and Table 3 show the resistance characteristics found by disk diffusion and by Etest, respectively. Fewer Etests were performed because of difficulty in obtaining test kits. Disk diffusion showed greater than $91 \%$ (364/399) resistance to

penicillin and greater than $99 \%(397 / 399 ; 399 / 399)$ resistance to both tetracycline and ciprofloxacin. A resistance of $1.06 \%$ $(2 / 188)$ to ceftriaxone and resistance or intermediate resistance of $2.1 \%$ (4/188) to azithromycin were found using Etest. Early samples $(n=116)$ collected from September 2016 to March 2017 underwent comprehensive microbiological analysis and 59.5\% 
of these (69/116) underwent complete Etest resistance profiles. Of these, $96 \%(66 / 69)$ were ciprofloxacin-resistant or ciprofloxacin-intermediate, no resistance $(0 / 69)$ to cefixime was demonstrated, and 96\% (66/69) of isolates were azithromycinand gentamicin-sensitive (Table 4).

The minimum inhibitory concentrations needed for inhibiting $50 \%$ of microbial growth for ceftriaxone, cefixime, gentamicin, ciprofloxacin, and azithromycin were $0.003 \mu \mathrm{g} / \mathrm{mL}, 0.0016$ $\mu \mathrm{g} / \mathrm{mL}, 3 \mu \mathrm{g} / \mathrm{mL}, 2 \mu \mathrm{g} / \mathrm{mL}$, and $0.19 \mu \mathrm{g} / \mathrm{mL}$, respectively. Additionally, 2 isolates demonstrated high-level resistance to azithromycin by Etest (minimum inhibitory concentrations $=12$ $\mu \mathrm{g} / \mathrm{mL}$ and $16 \mu \mathrm{g} / \mathrm{mL}$ ) and 1 isolate demonstrated intermediate resistance to azithromycin (minimum inhibitory concentration $=3$ $\mu \mathrm{g} / \mathrm{mL}$ ); 3 isolates were gentamicin-intermediate (all 3 with minimum inhibitory concentration $=6 \mu \mathrm{g} / \mathrm{mL}$ ) and were sensitive to azithromycin.

Table 2. Disk diffusion resistance characteristics.

\begin{tabular}{llllll}
\hline Antibiotics & Breakpoint in mm & ZOI $^{\mathrm{a}}$ range in mm & Resistant, $\mathrm{n}(\%)$ & $\frac{\text { Intermediate, } \mathrm{n}(\%)}{\text { Sensitive, } \mathrm{n}(\%)}$ \\
\hline Cefixime $(\mathrm{n}=395)$ & $\mathrm{S}^{\mathrm{b}} \geq 31$ & $28-60$ & $0(0)$ & $1^{\mathrm{c}}(0.25)$ & $394(99.7)$ \\
Ceftriaxone $(\mathrm{n}=397)$ & $\mathrm{S} \geq 35$ & $28-62$ & $2^{\mathrm{d}}(0.5)$ & $2^{\mathrm{d}}(0.5)$ & $393(99.0)$ \\
Ciprofloxacin $(\mathrm{n}=399)$ & $\geq 41$ & $0-27$ & $399(100)$ & $0(0)$ & $0(0)$ \\
Penicillin G $(\mathrm{n}=399)$ & $\geq 47$ & $10-52$ & $364(91.2)$ & $34(8.5)$ & $1(0.25)$ \\
Spectinomycin $(\mathrm{n}=34)$ & $\geq 18$ & $18-34$ & $0(0)$ & $1(2.9)$ & $33(97.1)$ \\
Tetracycline $(\mathrm{n}=399)$ & $\geq 38$ & $6-40$ & $397(99.5)$ & $1(0.25)$ & $1(0.25)$ \\
\hline
\end{tabular}

aOI: zone of inhibition.

${ }^{\mathrm{b}} \mathrm{S}$ : sensitive.

${ }^{\mathrm{c}} \mathrm{ZOI}$ of $28 \mathrm{~mm}$.

$\mathrm{d}_{2}$ had ZOI of $28 \mathrm{~mm}, 1$ had ZOI of $32 \mathrm{~mm}$, and 1 had ZOI of $34 \mathrm{~mm}$.

Table 3. Etest resistance characteristics.

\begin{tabular}{|c|c|c|c|c|c|c|c|}
\hline \multirow[t]{2}{*}{ Antibiotics } & \multicolumn{3}{|c|}{ Resistant } & \multicolumn{2}{|c|}{ Intermediate } & \multicolumn{2}{|l|}{ Sensitive } \\
\hline & Range $(\mu \mathrm{g} / \mathrm{mL})$ & $\mathrm{n}(\%)$ & $\begin{array}{l}\text { Breakpoint } \\
(\mu \mathrm{g} / \mathrm{mL})\end{array}$ & $\mathrm{n}(\%)$ & $\begin{array}{l}\text { Breakpoint } \\
(\mu \mathrm{g} / \mathrm{mL})\end{array}$ & $\mathrm{n}(\%)$ & $\begin{array}{l}\text { Breakpoint } \\
(\mu \mathrm{g} / \mathrm{mL})\end{array}$ \\
\hline Azithromycin $(\mathrm{n}=188)$ & $<0.016-16$ & $2(1.1)^{\mathrm{a}}$ & $\geq 8$ & $2(1.1)^{\mathrm{b}}$ & - & $184(97.9)$ & $\leq 2$ \\
\hline Cefixime ( $\mathrm{n}=185$ ) & $<0.016-0.16$ & $0(0)$ & - & - & - & $185(100)$ & $\leq 0.25^{\mathrm{c}}$ \\
\hline Ceftriaxone $(\mathrm{n}=188)$ & $0.002-1.5$ & $2(1.1)^{\mathrm{d}}$ & - & - & - & $186(98.9)$ & $\leq 0.25^{\mathrm{c}}$ \\
\hline Ciprofloxacin (n=192) & $0.002-32$ & $188(97.9)$ & $\geq 1$ & - & - & $4(2.1)^{\mathrm{e}}$ & $\leq 0.061$ \\
\hline Gentamicin $(\mathrm{n}=189)$ & $0.38-48$ & $1(0.5)^{\mathrm{f}}$ & $\geq 32$ & $3(1.6)^{\mathrm{g}}$ & $8-16$ & $185(97.9)$ & $\leq 4$ \\
\hline
\end{tabular}

${ }^{\mathrm{a}}$ Minimum inhibition concentrations (MIC) are noted here; 1 sample had MIC $=12 \mu \mathrm{g} / \mathrm{mL} ; 1$ sample had MIC $=16 \mu \mathrm{g} / \mathrm{mL}$.

$\mathrm{b}_{2}$ samples had $\mathrm{MIC}=3 \mu \mathrm{g} / \mathrm{mL}$.

$c_{2}$ samples had MIC $=0.125 \mu \mathrm{g} / \mathrm{mL}$.

${ }^{d} 1$ sample had MIC $=1.5 \mu \mathrm{g} / \mathrm{mL} ; 1$ sample had MIC $=0.5 \mu \mathrm{g} / \mathrm{mL}$.

e 2 samples had MIC $=0.02 \mu \mathrm{g} / \mathrm{mL} ; 1$ sample had MIC $=0.016 \mu \mathrm{g} / \mathrm{mL} ; 1$ sample had MIC $=0.008 \mu \mathrm{g} / \mathrm{mL}$.

${ }_{1} 1$ sample had $\mathrm{MIC}=48 \mu \mathrm{g} / \mathrm{mL}$.

$\mathrm{g}_{3}$ samples had MIC $=6 \mu \mathrm{g} / \mathrm{mL}$. 
Table 4. Percentage of isolates susceptible to the antibiotic tested.

\begin{tabular}{lll}
\hline Antibiotic & Disk diffusion & Etest $(\%)$ \\
\hline Azithromycin & $\mathrm{NT}^{\mathrm{a}}$ & 95.6 \\
Cefixime & 100 & 100 \\
Ciprofloxacin & 4.3 & 0.0 \\
Ceftriaxone & 99.0 & 97.0 \\
Cefuroxime & 100 & 90.0 \\
Cefoxitin & 84.0 & $\mathrm{NT}$ \\
Gentamicin & 25.0 & 95.7 \\
Penicillin & 0.0 & $\mathrm{NT}$ \\
Spectinomycin & 97.0 & $\mathrm{NT}$ \\
Tetracycline & 0.0 & $\mathrm{NT}$ \\
\hline
\end{tabular}

${ }^{\mathrm{a}} \mathrm{NT}$ : not tested.

The gonorrhea samples $(4 / 400,1 \%$ of culture-positive) that demonstrated decreased susceptibility to ceftriaxone by disk diffusion were different by Etest where resistance was set at $\geq 0.25 \mu \mathrm{g} / \mathrm{mL}$. In the 5 isolates with results by both methods, 2 were intermediate, 1 was resistant, and 2 were sensitive by disk diffusion, compared with 2 resistant and 3 sensitive by Etest; full details are in Multimedia Appendix 2. The $2(0.5 \%)$ gonorrhea isolates demonstrating intermediate or decreased minimum inhibitory concentration to cefixime by disk diffusion were found to be sensitive by Etest, when that test was performed, where resistance was set at $\geq 0.25 \mu \mathrm{g} / \mathrm{mL}$ (Multimedia Appendix 2). There were 4/188 (2.1\%) gonorrhea isolates that demonstrated intermediate or decreased minimum inhibitory concentration to azithromycin by Etest where sensitivity was set at $\leq 2.0 \mu \mathrm{g} / \mathrm{mL}$ (Multimedia Appendix 2).

Table 5 categorizes the data by gonorrhea culture-status. Men with HIV were significantly older $(P<.001)$. Self-reported HIV positivity of $7.2 \%$ was higher than the national $5.3 \%$ (range $5.0 \%-5.7 \%$ ) in men aged 15 to 49 years and substantially higher than the $1.9 \%$ reported in those aged 15 to 24 years reported by Joint United Nations Program on HIV/AIDS [25]. Rates of condom use were significantly different with men with HIV more likely to report always using a condom $(P<.001)$; these men were more likely to have accessed antibiotics prior to their clinic visit for urethritis $(P=.006$; data not shown). Men whose samples were gonorrhea culture-positive were younger $(P=.01)$ and less likely to always use condoms $(P=.003)$. Men who reported sometimes using condoms were more likely to be found $N$ gonorrhoeae culture-positive compared to those who never used condoms (Odds ratio [OR] 1.77, 95\% CI 1.23, 2.55). Men whose samples were $N$ gonorrhoeae culture-positive had fewer numbers of previous $N$ gonorrhoeae episodes than those whose samples were culture-negative $(P<.001)$; for every previous episode they had a 0.68 odds of being $N$ gonorrhoeae culture-positive. Only 43.3\% (173/400) of men whose samples were culture-positive had been prescribed the recommended treatment of an extended-spectrum cephalosporin and doxycycline as syndromic management of urethral discharge syndrome [26]. 
Table 5. Variables by gonorrhea culture-status.

\begin{tabular}{|c|c|c|c|c|c|}
\hline Variable & All $^{\mathrm{a}}, \mathrm{N}=639$ & Negative, $n=230$ & Positive, $n=400$ & Odds Ratio (95\% CI) & $P$ value \\
\hline Age, mean (SD) & $26.9(9.6)$ & $28.3(10.2)$ & $26.3(9.0)$ & $0.98(0.96,0.99)$ & .01 \\
\hline HIV-status, n (\%) & & & & & .67 \\
\hline Positive & $46(7.2)$ & $16(7.4)$ & $30(7.8)$ & $1.13(0.60,2.15)$ & \\
\hline Negative & $393(61.5)$ & $147(68.1)$ & $243(64.5)$ & REF & \\
\hline Unknown & $200(31.3)$ & $67(29.1)$ & $127(31.8)$ & $1.147(0.80,1.64)$ & \\
\hline Engage in commercial sex, $n(\%)$ & & & & & .13 \\
\hline Yes & $98(15.3)$ & $42(18.3)$ & $55(13.8)$ & $0.71(0.46,1.11)$ & \\
\hline No & $541(84.7)$ & $188(81.7)$ & $345(86.3)$ & REF & \\
\hline Condom use $^{\mathbf{b}}, \mathbf{n}(\%)$ & & & & & .003 \\
\hline Always & $18(3.0)$ & $8(3.8)$ & $7(1.9)$ & $0.71(0.25,2.05)$ & \\
\hline Sometimes & $403(67.5)$ & $126(59.4)$ & $274(72.7)$ & $1.77(1.23,2.55)$ & \\
\hline Never & $176(29.5)$ & $78(36.8)$ & $96(25.5)$ & REF & \\
\hline Previous episodes of gonorrhea ${ }^{c}, \mathbf{n}$ & & & & $0.68(0.56,0.83)$ & $<.001$ \\
\hline mean $(\mathrm{SD})$ & $0.43(0.87)$ & $0.62(1.13)$ & $0.32(0.66)$ & N/A & \\
\hline range & $0-8$ & $0-8$ & $0-3$ & N/A & \\
\hline Number of sex partners ${ }^{\mathrm{d}}$, mean $(\mathrm{SD})$ & $1.4(1.7)$ & $1.4(2.0)$ & $1.4(1.5)$ & $0.99(0.91,1.10)$ & .98 \\
\hline Recent antibiotic use, n (\%) & & & & $0.73(0.52,1.02)$ & .07 \\
\hline Yes & 209 (32.7) & $86(37.4)$ & $121(30.3)$ & N/A & \\
\hline No & $430(67.3)$ & $144(62.6)$ & $279(69.8)$ & N/A & \\
\hline Antibiotic therapy ${ }^{\mathrm{e}}, \mathrm{n}(\%)$ & & & & & .17 \\
\hline Correct combination & $254(42.3)$ & $85(39.7)$ & $173(43.3)$ & REF & \\
\hline $\begin{array}{l}\text { Correct combination plus metronidazole or } \\
\text { tinidazole }\end{array}$ & $199(33.2)$ & $65(30.4)$ & $132(35.0)$ & $0.94(0.64,1.40)$ & \\
\hline Overtreatment & $42(7.0)$ & $19(8.9)$ & $23(6.1)$ & $1.58(0.82,3.07)$ & \\
\hline Incorrect antibiotic combination & $106(17.5)$ & $45(21.0)$ & $59(15.7)$ & $1.46(0.92,2.34)$ & \\
\hline
\end{tabular}

$a_{n=9}$ missing culture-status.

${ }^{b}=42$ responses were missing.

$\mathrm{c}_{\mathrm{n}}=21$ responses were missing.

$\mathrm{d}_{\mathrm{n}=7}$ responses were missing.

$\mathrm{e}_{\mathrm{n}=38}$ responses were missing.

\section{Discussion}

\section{Principal Findings}

The WHO STI guidelines currently recommend that reliable and recent local resistance data should guide the choice of either single or dual therapy for genital and anorectal gonococcal infection [27]. While agar dilution is considered the gold standard for determining antimicrobial susceptibility of $N$ gonorrhoeae [28], it is labor-intensive and requires technical expertise that is often not available in resource-limited settings. Disk diffusion is widely used in microbiology laboratories for antibiotic-sensitivity testing, but reproducibility is a significant issue. While Etests are more reliable, simpler, and faster to perform, and its results have demonstrated acceptable agreement with those from agar dilution [29,30], the cost of Etests may be an issue in resource-limited settings. Our data demonstrate good concordance between resistance measured by disk diffusion and that measured by Etest for most antibiotics that were tested (with the exception of gentamicin). For other antibiotics, where comparison between methods was possible, discordance ranged from $0 \%$ to $10 \%$. The reason for the $71 \%$ difference between the two different sensitivity-testing methods for gentamicin is not known and requires further investigation. Gentamicin's Etest results are most likely to be correct; similar, though less pronounced differences by assay type have been reported [31].

In Uganda, between 1993 and 2010, ciprofloxacin was the recommended first-line antibiotic for presumptive gonorrhea. Since 2012, Ugandan Clinical Guidelines recommend a single dose of cefixime with doxycycline taken over 7 days for syndromic management of urethral discharge syndrome [26]. 
The antimicrobial resistance profiles reported here have profound public health implications; they support arguments for expanded surveillance programs and investment in first-line antibiotic supplies which could improve population health and slow the spread of antimicrobial-resistant gonorrhea in Uganda. In 2018, the annual cost of EGASP in Kampala was approximately 247,000,000 UGX (US \$64,996; an exchange of $1 \mathrm{UGX}=\mathrm{US} \$ 0.0026$ was applied). Of the total, $23 \%$ of costs were for antimicrobial testing, $4 \%$ for clinic staff, and $17 \%$ for the sites.

Recently, ceftriaxone-resistant gonorrhea strains have been found in Asia, Europe, and North America [8,11,32]. High-level azithromycin resistance has also been reported [7,10]. This marks a low point in the battle against antimicrobial-resistant gonorrhea since both ceftriaxone and azithromycin are recommended by the Centers for Disease Control and Prevention and other agencies as first-line therapies [27,33]. As a result, the Centers for Disease Control and Prevention and WHO have called for the strengthening of global surveillance [20]; in Africa, surveillance has been inadequate or virtually absent [34]. The emergence of gonorrhea with decreased sensitivity to current first-line antibiotics raises the specter of untreatable multidrug resistance. $N$ gonorrhoeae has evolved to outpace every new class of antibiotic that has been routinely used in its treatment. The pipeline for new antigonococcal therapies is narrow with no readily available, affordable, and orally administered drugs close to being accessible for routine clinical use [5]. New drugs such as the novel oral fluoroketolide or solithromycin show potential but are not FDA-approved, and the recycling of older drugs, such as gentamicin, is limited by potential toxicity and less-than-ideal effectiveness $(<92 \%$ microbiological cure). Even carbapenems are not guaranteed to have enduring efficacy since extended-spectrum cephalosporin resistance determinants (for example, mosaic penA alleles, mtrR, and penB) also increase the ertapenem minimum inhibitory concentration [12].

Antimicrobial resistance can readily develop in sub-Saharan Africa because of limited surveillance and poor antimicrobial stewardship. The feasibility of undertaking gonorrhea surveillance in a resource-limited setting on a relatively large scale has been established [35]. It is likely that urethral discharge syndrome represents a small portion of actual antibiotic resistance since cervical, rectal, and pharyngeal infections are often asymptomatic [36,37].

These data reveal a population with higher than national average HIV prevalence $(7.2 \%$ versus $5.3 \%$ ), substantial rates of transactional sex $(15.3 \%)$, a high number of partners, and very low consistent condom-use (less than 3.0\%). Those who reported sometimes using condoms in comparison to those who reported never using condoms were found to be $N$ gonorrhoeae culture-positive more often. This counterintuitive finding may reflect that men who engaged in lower-risk sexual encounters with regular partners were less likely to use condoms but requires further exploration. Men with previous episodes of gonorrhea were found to be less likely to have a positive $N$ gonorrhoeae culture. The explanation for this is not clear but may reflect differences in antibiotic use prior to attending clinic, or raises the possibility of unexplained, modest, inducible immune responses to repeated $N$ gonorrhoeae infection [38]. Less than $50 \%$ received recommended first-line antibiotic treatment. Even in high-resource countries such as the United States, in 2016, approximately $20 \%$ of individuals received nonrecommended regimens for gonorrhea [39]. Ciprofloxacin use was common despite its almost universal resistance; indeed, ciprofloxacin antimicrobial resistance appears to have increased dramatically in the past decade from $83.1 \%$ in 2008 and 2009 [18] to $97.9 \%$ in this analysis (measured by Etest). Azithromycin resistance has increased from $2.7 \%$ in 2008 and 2009 [18] to $4 \%$ in this analysis. In 2008 and 2009, there was no documented cefixime resistance which should offer some reassurance, since cefixime is a WHO and Ugandan recommended first-line treatment; however, anecdotal evidence suggests that cefixime is generally unavailable in STI clinics, and that patients are unable to afford the drug. Cefixime's continued potency may be the result of its own scarcity. Data on same-sex sexual activity were not collected, since disclosure could be potentially dangerous [24]. The Joint United Nations Program on HIV/AIDS reported a much higher rate of HIV in Ugandan men who have sex with men $(13.2 \%)$ than that in men who have sex with women $(5.3 \%)$ [25], so it is likely that $N$ gonorrhoeae prevalence is also higher, particularly at extragenital sites. There were low rates of antimicrobial resistance to both gentamicin and extended-spectrum cephalosporins, but they were measurable so, nevertheless, require monitoring. In contrast, there was no recorded gentamicin resistance in Malawi in 2007 [31]. The finding of isolates $(4 / 188,2.1 \%)$ with increased minimum inhibitory concentration to azithromycin was concerning since, in many regions, azithromycin is a common component of dual $N$ gonorrhoeae therapy [33], and Uganda may be compelled to follow suit given the extremely high rates of doxycycline resistance.

There was overtreatment in up to $11.6 \%$ of men which included oral cefixime and parenteral ceftriaxone in the same individual. Only 414/639 (64.8\%) of men presenting with discharge had Gram-negative intracellular diplococci on Gram stain or a positive gonorrhea culture, compared with $73.5 \%$ in an earlier Zimbabwean study [40] that used multiplex polymerase chain reaction which is more sensitive than culture. The remaining $35.2 \%$ had, by definition, nongonococcal urethritis and were likely to have other unrecognized STIs.

\section{Limitations}

The study was limited by several factors including the lack of biochemical or molecular testing to confirm nutrient requirements and that typical morphologies and oxidase reactions represented $N$ gonorrhoeae rather than related Neisseria species. In addition, the data on previous gonorrheaand HIV-status were collected by self-report and $31.3 \%$ of the men were not aware of, or did not report, their HIV-status. There was no clinical outcome data, and the nature of antibiotic treatment taken prior to clinic attendance was unknown. Of the 414 samples with Gram-negative intracellular diplococci on microscopy, 400 (96.6\%) were $N$ gonorrhoeae culture-positive while the remainder resulted in nonsignificant growth which could represent culture failure or the presence of other morphologically similar species. Firm conclusions about concordance between antibiotic sensitivity methods in the 
samples that demonstrated intermediate or decreased minimum inhibitory concentration to azithromycin is difficult because of incomplete testing by both methods.

We had no data on same-sex activity or extragenital exposures nor did we have data on the prevalence of other STIs. Finally, different data collection or case report forms were used; therefore, some of the data points were collected across different periods (over 6 months versus 12 months) which may have influenced recall bias.

\section{Conclusion}

Data on $N$ gonorrhoeae resistance in sub-Saharan Africa have been lacking to date, with the exception of sporadic studies and reports [21,22,41], and more recently, increasing systematic efforts [35]. This study has clearly demonstrated resistance to and increased minimum inhibitory concentration for vital antigonococcal antibiotics. It supports the hypothesis that several antibiotics are obsolete for use in the treatment of gonorrhea in Uganda. Ciprofloxacin resistance is much higher in Uganda than described elsewhere despite its removal from treatment guidelines more than 5 years ago—resistance to it has persisted and ciprofloxacin cannot be recycled. Measurable azithromycin and gentamicin resistance and decreased sensitivity as well as increasing minimum inhibitory concentration for ceftriaxone are worrisome. With selection pressure being exerted by the frequent use of extended-spectrum cephalosporins for numerous febrile illnesses in Africa, it may not be long before these strains are endemic in Uganda. There were very high rates of sexual risk in this population and there is a need for prevention interventions such as HIV pre-exposure prophylaxis. Antimicrobial stewardship programs in conjunction with continued surveillance will be critical in preventing the expansion of antimicrobial-resistant gonorrhea and will be important for filling gaps in knowledge, identifying emerging trends, and creating data-driven action plans.

\section{Acknowledgments}

The authors would like to acknowledge patients and clinicians at sentinel clinic sites for providing samples, the Centers for Disease Control and Prevention, Division of Sexually Transmitted Disease Prevention for sharing the original EGASP protocol as well as for providing Etest strips for the program, and in particular, John Papp, Emily Watson, and Mary Kamb at the Centers for Disease Control and Prevention and Theodora Wi at World Health Organization. The work was supported by the Centers for Disease Control Global Health Security grant. MW was supported by the National Institute of Health grant T32 AI007291-27. YCM was also supported by the National Institute of Biomedical Imaging and Bioengineering at the National Institutes of Health for the Johns Hopkins Center for Point of Care Technologies Research Network (U54EB007958). The content is solely the responsibility of the authors and does not necessarily represent the official views of the National Institutes of Health or Centers for Disease Control and Prevention.

\section{Conflicts of Interest}

None declared.

\section{Multimedia Appendix 1}

Ugandan National treatment guidelines.

[DOCX File, 63 KB-Multimedia Appendix 1]

\section{Multimedia Appendix 2}

Additional results.

\section{[DOCX File, 19 KB-Multimedia Appendix 2]}

\section{References}

1. Hook EW, Handsfield HH. Gonococcal infections in the adult. In: Holmes KK, Sparling PF, Stamm WE, Piot P, Wasserheit JN, Corey L, et al, editors. Sexually Transmitted Diseases. 4th ed. New York: McGraw-Hill Education; 2007:627-645.

2. Fleming DT, Wasserheit JN. From epidemiological synergy to public health policy and practice: the contribution of other sexually transmitted diseases to sexual transmission of HIV infection. Sex Transm Infect 1999 Feb 01;75(1):3-17 [FREE Full text] [doi: 10.1136/sti.75.1.3] [Medline: 10448335]

3. Rowley J, Vander Hoorn S, Korenromp E, Low N, Unemo M, Abu-Raddad LJ, et al. Chlamydia, gonorrhoea, trichomoniasis and syphilis: global prevalence and incidence estimates, 2016. Bull World Health Organ 2019 Aug 01;97(8):548-562P [FREE Full text] [doi: 10.2471/BLT.18.228486] [Medline: 31384073]

4. Newman L, Rowley J, Vander Hoorn S, Wijesooriya NS, Unemo M, Low N, et al. Global estimates of the prevalence and incidence of four curable sexually transmitted infections in 2012 based on systematic review and global reporting. PLoS One 2015;10(12):e0143304 [FREE Full text] [doi: 10.1371/journal.pone.0143304] [Medline: 26646541]

5. Unemo M, Shafer WM. Antimicrobial resistance in Neisseria gonorrhoeae in the 21st century: past, evolution, and future. Clin Microbiol Rev 2014 Jul;27(3):587-613 [FREE Full text] [doi: 10.1128/CMR.00010-14] [Medline: 24982323] 
6. Yong D, Kim TS, Choi JR, Yum JH, Lee K, Chong Y, et al. Epidemiological characteristics and molecular basis of fluoroquinolone-resistant Neisseria gonorrhoeae strains isolated in Korea and nearby countries. J Antimicrob Chemother 2004 Aug;54(2):451-455. [doi: 10.1093/jac/dkh345] [Medline: 15231766]

7. Chisholm SA, Dave J, Ison CA. High-level azithromycin resistance occurs in Neisseria gonorrhoeae as a result of a single point mutation in the 23S rRNA genes. Antimicrob Agents Chemother 2010 Sep;54(9):3812-3816 [FREE Full text] [doi: 10.1128/AAC.00309-10] [Medline: 20585125]

8. Lefebvre B, Martin I, Demczuk W, Deshaies L, Michaud S, Labbé AC, et al. Ceftriaxone-resistant Neisseria gonorrhoeae, Canada, 2017. Emerg Infect Dis 2018 Feb;24(2) [FREE Full text] [doi: 10.3201/eid2402.171756] [Medline: 29131780]

9. Lewis DA, Sriruttan C, Müller EE, Golparian D, Gumede L, Fick D, et al. Phenotypic and genetic characterization of the first two cases of extended-spectrum-cephalosporin-resistant Neisseria gonorrhoeae infection in South Africa and association with cefixime treatment failure. J Antimicrob Chemother 2013 Jun;68(6):1267-1270. [doi: 10.1093/jac/dkt034] [Medline: 23416957]

10. Katz A, Komeya A, Kirkcaldy R, Whelen AC, Soge OO, Papp JR, et al. Cluster of Neisseria gonorrhoeae isolates with high-level azithromycin resistance and decreased ceftriaxone susceptibility, Hawaii, 2016. Clin Infect Dis 2017 Sep 15;65(6):918-923 [FREE Full text] [doi: 10.1093/cid/cix485] [Medline: 28549097]

11. Lahra MM, Martin I, Demczuk W, Jennison AV, Lee K, Nakayama S, et al. Cooperative recognition of internationally disseminated ceftriaxone-resistant Neisseria gonorrhoeae strain. Emerg Infect Dis 2018 Apr;24(4) [FREE Full text] [doi: 10.3201/eid2404.171873] [Medline: 29553335]

12. Unemo M, Golparian D, Limnios A, Whiley D, Ohnishi M, Lahra MM, et al. In vitro activity of ertapenem versus ceftriaxone against Neisseria gonorrhoeae isolates with highly diverse ceftriaxone MIC values and effects of ceftriaxone resistance determinants: ertapenem for treatment of gonorrhea? Antimicrob Agents Chemother 2012 Jul;56(7):3603-3609 [FREE Full text] [doi: 10.1128/AAC.00326-12] [Medline: 22547617]

13. Affolabi D, Goma E, Sogbo F, Ahotin G, Orekan J, Massou F, et al. Antimicrobial susceptibility profile of Neisseria gonorrhoeae isolated in Cotonou, Benin (2015-2017). Sex Transm Infect 2018 Feb;94(1):20. [doi: 10.1136/sextrans-2017-053340] [Medline: 29021407]

14. Ali S, Sewunet T, Sahlemariam Z, Kibru G. Neisseria gonorrhoeae among suspects of sexually transmitted infection in Gambella hospital, Ethiopia: risk factors and drug resistance. BMC Res Notes 2016 Sep 13;9(1):439 [FREE Full text] [doi: 10.1186/s13104-016-2247-4] [Medline: 27619365]

15. Hailemariam M, Abebe T, Mihret A, Lambiyo T. Prevalence of Neisseria gonorrhea and their antimicrobial susceptibility patterns among symptomatic women attending gynecology outpatient department in Hawassa referral hospital, Hawassa, Ethiopia. Ethiop J Health Sci 2013 Mar;23(1):10-18 [FREE Full text] [Medline: 23559833]

16. Tibebu M, Shibabaw A, Medhin G, Kassu A. Neisseria gonorrhoeae non-susceptible to cephalosporins and quinolones in Northwest Ethiopia. BMC Infect Dis 2013 Sep 05;13:415 [FREE Full text] [doi: 10.1186/1471-2334-13-415] [Medline: 24007340]

17. Takuva S, Mugurungi O, Mutsvangwa J, Machiha A, Mupambo AC, Maseko V, et al. Etiology and antimicrobial susceptibility of pathogens responsible for urethral discharge among men in Harare, Zimbabwe. Sex Transm Dis 2014 Dec;41(12):713-717. [doi: 10.1097/OLQ.0000000000000204] [Medline: 25581806]

18. Vandepitte J, Hughes P, Matovu G, Bukenya J, Grosskurth H, Lewis DA. High prevalence of ciprofloxacin-resistant gonorrhea among female sex workers in Kampala, Uganda (2008-2009). Sex Transm Dis 2014 Apr;41(4):233-237. [doi: 10.1097/OLQ.0000000000000099] [Medline: 24622633]

19. Mabonga E, Parkes-Ratanshi R, Riedel S, Nabweyambo S, Mbabazi O, Taylor C, et al. Complete ciprofloxacin resistance in gonococcal isolates in an urban Ugandan clinic: findings from a cross-sectional study. Int J STD AIDS 2019 Mar 04;30(3):256-263 [FREE Full text] [doi: 10.1177/0956462418799017] [Medline: 30392463]

20. Weston EJ, Wi T, Papp J. Strengthening global surveillance for antimicrobial drug-resistant Neisseria gonorrhoeae through the Enhanced Gonococcal Antimicrobial Surveillance Program. Emerg Infect Dis 2017 Oct;23(13) [FREE Full text] [doi: 10.3201/eid2313.170443] [Medline: 29155673]

21. World Health Organization. Baseline report on global sexually transmitted infection surveillance. 2012. URL: https://www. who.int/reproductivehealth/publications/rtis/9789241505895/en/ [accessed 2019-12-17]

22. Wi T, Lahra MM, Ndowa F, Bala M, Dillon JR, Ramon-Pardo P, et al. Antimicrobial resistance in Neisseria gonorrhoeae: global surveillance and a call for international collaborative action. PLoS Med 2017 Jul 7;14(7):e1002344 [FREE Full text] [doi: 10.1371/journal.pmed.1002344] [Medline: 28686231]

23. Latif AS, Gwanzura L, Machiha A, Ndowa F, Tarupiwa A, Gudza-Mugabe M, et al. Antimicrobial susceptibility in isolates from five sentinel surveillance sites in Zimbabwe, 2015-2016. Sex Transm Infect 2018 Feb 05;94(1):62-66. [doi: 10.1136/sextrans-2016-053090] [Medline: 28476914]

24. Agardh A, Ross M, Östergren PO, Larsson M, Tumwine G, Månsson SA, et al. Health risks in same-sex attracted Ugandan university students: evidence from two cross-sectional studies. PLoS One 2016;11(3):e0150627 [FREE Full text] [doi: 10.1371/journal.pone.0150627] [Medline: 26982494]

25. UNAIDS. Country factsheets Uganda.: UNAIDS; 2016. URL: http://www.unaids.org/en/regionscountries/countries/uganda [accessed 2019-07-09] 
26. The Republic of Uganda Ministry of Health. Uganda. 2016. Uganda Clinical Guidelines 2016: National Guidelines for Management of Common Conditions URL: http://www.health.go.ug/sites/default/files/ Uganda\%20Clinical\%20Guidelines\%202016 FINAL.pdf [accessed 2018-04-06]

27. World Health Organization. Geneva. 2016. WHO guidelines for the treatment of Neisseria gonorrhoeae URL: https://www. who.int/reproductivehealth/publications/rtis/gonorrhoea-treatment-guidelines/en/ [accessed 2018-04-06]

28. World Health Orgaization. Manual for the laboratory identification and antimicrobial susceptibility testing of bacterial pathogens of public health concern in the developing world. 2003. URL: https://www.who.int/csr/resources/publications/ drugresist/en/IAMRmanual.pdf?ua=1 [accessed 2018-12-17]

29. Liu H, Taylor TH, Pettus K, Johnson S, Papp JR, Trees D. Comparing the disk-diffusion and agar dilution tests for antimicrobial susceptibility testing. Antimicrob Resist Infect Control 2016 Nov 24;5(1):46 [FREE Full text] [doi: 10.1186/s13756-016-0148-x] [Medline: 27904747]

30. Liu H, Taylor TH, Pettus K, Trees D. Assessment of Etest as an alternative to agar dilution for antimicrobial susceptibility testing of Neisseria gonorrhoeae. J Clin Microbiol 2014 Feb 19;52(5):1435-1440. [doi: 10.1128/jcm.02131-13] [Medline: 24554750]

31. Brown LB, Krysiak R, Kamanga G, Mapanje C, Kanyamula H, Banda B, et al. Neisseria gonorrhoeae antimicrobial susceptibility in Lilongwe, Malawi, 2007. Sexually Transmitted Diseases 2010;37(3):169-172. [doi:

10.1097/olq.0b013e3181bf575c] [Medline: 19901860]

32. Chen S, Yin Y, Chen X. Cephalosporin-resistant Neisseria gonorrhoeae clone, China. Emerg Infect Dis 2018 Apr;24(4):804-806 [FREE Full text] [doi: 10.3201/eid2404.171817] [Medline: 29553336]

33. Workowski KA, Bolan GA, Centers for Disease ControlPrevention. Sexually transmitted diseases treatment guidelines, 2015. MMWR Recomm Rep 2015 Jun 05;64(RR-03):1-137. [Medline: 26042815]

34. Latif AS, Gwanzura L, Machiha A, Ndowa F, Tarupiwa A, Gudza-Mugabe M, et al. Antimicrobial susceptibility in isolates from five sentinel surveillance sites in Zimbabwe, 2015-2016. Sex Transm Infect 2018 Feb;94(1):62-66. [doi: 10.1136/sextrans-2016-053090] [Medline: 28476914]

35. Yéo A, Kouamé-Blavo B, Kouamé CE, Ouattara A, Yao AC, Gbedé BD, et al. Establishment of a Gonococcal Antimicrobial Surveillance Programme, in accordance with World Health Organization standards, in Côte d'Ivoire, Western Africa, 2014-2017. Sex Transm Dis 2019 Mar;46(3):179-184. [doi: 10.1097/OLQ.0000000000000943] [Medline: 30461598]

36. Chan P, Robinette A, Montgomery M, Almonte A, Cu-Uvin S, Lonks JR, et al. Extragenital infections caused by Chlamydia trachomatis and Neisseria gonorrhoeae: a review of the literature. Infect Dis Obstet Gynecol 2016;2016:5758387 [FREE Full text] [doi: 10.1155/2016/5758387] [Medline: 27366021]

37. Detels R, Green AM, Klausner JD, Katzenstein D, Gaydos C, Handsfield HH, et al. The incidence and correlates of symptomatic and asymptomatic Chlamydia trachomatis and Neisseria gonorrhoeae infections in selected populations in five countries. Sex Transm Dis 2011 Jun;38(6):503-509 [FREE Full text] [Medline: 22256336]

38. Lovett A, Duncan JA. Human immune responses and the natural history of Neisseria gonorrhoeae infection. Front Immunol 2018;9:3187. [doi: 10.3389/fimmu.2018.03187] [Medline: $\underline{30838004]}$

39. Weston EJ, Workowski K, Torrone E, Weinstock H, Stenger MR. Adherence to CDC recommendations for the treatment of uncomplicated gonorrhea - STD Surveillance Network, United States, 2016. MMWR Morb Mortal Wkly Rep 2018 Apr 27;67(16):473-476 [FREE Full text] [doi: 10.15585/mmwr.mm6716a4] [Medline: 29698384]

40. Rietmeijer CA, Mungati M, Machiha A, Mugurungi O, Kupara V, Rodgers L, et al. The etiology of male urethral discharge in Zimbabwe: results from the Zimbabwe STI etiology study. Sex Transm Dis 2018 Jan;45(1):56-60. [doi:

10.1097/OLQ.0000000000000696] [Medline: 29240635]

41. World Heath Organization. Antimicrobial resistance: Global report on surveillance. 2014. URL: https://apps.who.int/iris/ bitstream/handle/10665/112642/9789241564748_eng.pdf [accessed 2018-12-17]

\author{
Abbreviations \\ EGASP: Enhanced Gonococcal Antimicrobial Surveillance Program \\ FDA: Food and Drug Administration \\ GASP: Gonococcal Antimicrobial Surveillance Program \\ GNID: gram-negative intracellular diplococci \\ HIV: Human Immunodeficiency Virus \\ MIC: minimum inhibitory concentration \\ OR: odds ratio \\ STI: sexually transmitted infection \\ UGX: Ugandan shilling \\ WHO: World Health Organization \\ ZOI: zone of inhibition
}


Edited by T Sanchez; submitted 15.11.19; peer-reviewed by D Mabey, P Banik; comments to author 10.04.20; revised version received 18.04.20; accepted 20.04.20; published 10.06.20

Please cite as:

Workneh M, Hamill MM, Kakooza F, Mande E, Wagner J, Mbabazi O, Mugasha R, Kajumbula H, Walwema R, Zenilman J, Musinguzi $P$, Kyambadde P, Lamorde M, Manabe YC

Antimicrobial Resistance of Neisseria Gonorrhoeae in a Newly Implemented Surveillance Program in Uganda: Surveillance Report JMIR Public Health Surveill 2020;6(2):e17009

URL: http://publichealth.jmir.org/2020/2/e17009/

doi: $10.2196 / 17009$

PMID: 32519969

CMeklit Workneh, Matthew M Hamill, Francis Kakooza, Emmanuel Mande, Jessica Wagner, Olive Mbabazi, Rodney Mugasha, Henry Kajumbula, Richard Walwema, Jonathan Zenilman, Patrick Musinguzi, Peter Kyambadde, Mohammed Lamorde, Yukari C Manabe. Originally published in JMIR Public Health and Surveillance (http://publichealth.jmir.org), 10.06.2020. This is an open-access article distributed under the terms of the Creative Commons Attribution License (https://creativecommons.org/licenses/by/4.0/), which permits unrestricted use, distribution, and reproduction in any medium, provided the original work, first published in JMIR Public Health and Surveillance, is properly cited. The complete bibliographic information, a link to the original publication on http://publichealth.jmir.org, as well as this copyright and license information must be included. 